\title{
Comparative Evaluation of the Role of Sonography in Diagnosis of Acute Appendicitis versus Surgeon's Clinical Impression
}

\author{
A N AHMAD *N FATIMA R A HUSSAIN S.N.R.QADIR. \\ Department of Surgery \& *Community Medicine Jinnah Hospital/ AIMC \\ Correspondence to Dr. Ahsen Nazir, Senior Registrar Surgery
}

\begin{abstract}
A randomly selected group of patients presented in Accidents \& Emergency department of Jinnah hospital Lahore with complaint of acute lower abdominal pain were subjected to abdominal sonography and those positive for acute appendicitis on ultrasound examination were operated. Another group of randomly selected patients with acute lower abdominal pain in Emergency department were clinically evaluated for acute appendicitis and surgery was done based on clinical impression (history and classical signs for acute appendicitis). Ultrasound examination showed the following parameters. Sensitivity $71.8 \%$, specificity $62.5 \%$, PPV $88.4 \%$, NPV $35.7 \%$. Clinical evaluation showed the sensitivity of $95.2 \%$, specificity $77.7 \%$, PPV $90.9 \%$, NPV $87.5 \%$. It was concluded on the basis of the results that clinical evaluation of the patient is more sensitive in correctly categorizing those who need appendicectomy than the ultrasound examination. Although the latter can be used in suspected cases and to rule out other pathological conditions resulting in acute abdomen. Limitations: Clinical judgment to a large extent rest on the experience and expertise of the surgeon and so is the quality of sonographic results, which depend on experience of sonographer \& quality of ultrasound machine.
\end{abstract}

Key words: Sonography, acute appendicitis, clinical impression

Appendicitis is present since the time immortal. It is the most common cause of emergency surgery throughout the world. It is routinely diagnosed clinically, however vague symptomatology sometimes pose problems in diagnosis and put the clinician in a diagnostic dilemma to operate or to adopt the policy of wait and see. Failure to operate at times may result in perforation leading to excessive morbidity and mortality on one hand while unnecessary surgery and removal of normal appendix may result in additional cost and inconvenience to the patient in addition to complications of surgery such as wound infection, DVT $\&$ chest infection.

\section{Literature Review:}

The history of appendicitis dates back to centuries when adhesions in right iliac fossa in an Egyptian mummy in the Byzantine era suggested old appendicitis. In 1735 , Claudius Amyand performed the first appendicectomy of a boy who presented with a discharging sinus. The appendix was found to be perforated on surgery. Appendicectomy was done $\&$ the boy made remarkable recovery'.

Lehman used ultrasound for abdominal \& pelvic pathologies in 1960s.It's use for diagnosis of appendicitis started in 1980s and progressively the results obtained were good enough for surgeons to rely upon in doubtful cases $^{2}$.

\section{Study Objective}

To compare sonographic findings with the clinical dgment of surgeons in diagnosis of acute appendicitis.

Research Methodology

atients randomly chosen who presented in Accident's \& mergency department of Jinnah hospital Lahore with acute abdomen were clinically evaluated for acute appendicitis \& those with strong clinical suspicion were subjected to laprotomy. Another group of randomly selected patients also with acute abdomen were send for ultrasonography \& those with positive findings were operated for acute appendicitis.

\section{Results}

Cross tabulation between surgeon's clinical impression and surgical findings for acute appendicitis

\begin{tabular}{|c|c|c|c|}
\hline $\begin{array}{l}\text { Clinical } \\
\text { impression }\end{array}$ & $\begin{array}{l}\text { Surgically } \\
\text { proved } \\
\text { appendicitis }\end{array}$ & $\begin{array}{l}\text { Normal appendix } \\
\text { on surgery }\end{array}$ & Total \\
\hline Positive & 20 Tp (a) & $\mathrm{Fp}(\mathrm{b})$ & 22 \\
\hline Negative & 1 Fn (c) & $\operatorname{Tn}(\mathrm{d})$ & 8 \\
\hline Total & 21 & 9 & 30 \\
\hline $\begin{array}{l}\mathrm{Tp}=\text { true pos } \\
\mathrm{Tn}=\text { true neo } \\
\mathrm{Fn}=\text { false ne } \\
\mathrm{Fp}=\text { false po }\end{array}$ & & & \\
\hline \multicolumn{4}{|c|}{ Sensitivity $=\underline{a} \times 100=\frac{20 \times 100}{a+c} 21$} \\
\hline \multicolumn{4}{|c|}{ Specificity $=\underset{b+d}{d} \times 100=\frac{7}{9} \times 100=77.7 \%$} \\
\hline PPV & $0=\frac{20}{22} \times 100=90.9$ & $\%$ & \\
\hline NPV & $=\frac{7}{8} \times 100=87.5$ & $\%$ & \\
\hline
\end{tabular}

Sensitivity of ultrasonography in diagnosis of acute appendicitis was $71.8 \%$ as compared to clinical evaluation with sensitivity of $95.2 \%$. Sensitivity is the ability of the test to accurately categorize those who suffer from a disease.

Specificity of ultrasonographic test was $62.5 \%$ as compared to clinical evaluation with specificity of $77.7 \%$. 
Specificity is the ability of the test to correctly categorize those who do not suffer from a specific disease or condition in question.

Cross tabulation between ultrasonographic findings and surgical findings for acute appendicitis

\begin{tabular}{|c|c|c|c|}
\hline $\begin{array}{l}\text { Ultrasonographic } \\
\text { test result }\end{array}$ & $\begin{array}{l}\text { Surgically } \\
\text { proved } \\
\text { appendicitis }\end{array}$ & $\begin{array}{l}\text { Normal } \\
\text { appendix } \\
\text { on surgery }\end{array}$ & Total \\
\hline Positive & $23 \mathrm{Tp}(\mathrm{a})$ & $3 \mathrm{Fp}(\mathrm{b})$ & 26 \\
\hline \multirow[t]{2}{*}{ Negative } & 9 Fn (c) & $5 \operatorname{Tn}(\mathrm{d})$ & 14 \\
\hline & 32 & 8 & 40 \\
\hline \multicolumn{4}{|l|}{$\mathrm{Tp}=$ true positives } \\
\hline \multicolumn{4}{|l|}{$\mathrm{Tn}=$ true negatives } \\
\hline \multicolumn{4}{|l|}{$\mathrm{Fn}=$ false negatives } \\
\hline \multicolumn{4}{|l|}{$\mathrm{Fp}=$ false positives } \\
\hline \multicolumn{4}{|c|}{ Sensitivity $=\underline{\mathrm{a}} \times 100=71.8 \%$} \\
\hline \multirow{2}{*}{\multicolumn{4}{|c|}{ 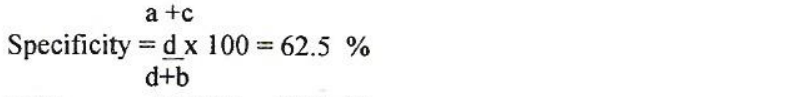 }} \\
\hline & & & \\
\hline$=\underline{a} \times 100=$ & $3.4 \%$ & & \\
\hline$=\frac{d}{d+b} \times 100=$ & $.7 \%$ & & - \\
\hline
\end{tabular}

Positive predictive value for ultrasonographic examination was $88.4 \%$ and for clinical diagnosis was $90.9 \%$. PPV is the likelihood of having the disease when test results are positive. It is more important from a clinician 's point of view.

Negative predictive value for ultrasonography was $35.7 \%$ and for clinical assessment was $87.5 \%$. NPV is the likelihood of not having the disease in question when test results are negative.

\section{Discussion}

Parameters for clinical evaluation that is, Sensitivity, Specificity, PPV, NPV are all high as compared to the ultrasonographic examination indicating that the diagnosis of acute appendicitis based on clinical judgment is far superior than diagnosis based on sonography. However the PPV of ultrasonography is also high showing that the technique can be used reliably for those who test positive. Ultrasonographic findings to a large extent depend on the experience of sonographer, the quality of machine and probe and the position of appendix.

It is therefore concluded that it can be used as a supportive technique where it is available free of cost. However the diagnosis should primarily rest on clinical judgment Sonographic evaluation can be done to rule out other abdominal conditions mimicking the symptoms of acute appendicitis when the surgeon is in doubt.

\section{References}

1. William Gr.Presidential address: A history of appendicitis. Ann Surg 1983: 197:495-506.

2. Goldberg BB, Gramiak R, Fremanis AK. Early history of diagnostic ultrasound. The role of American Radiologists. AmJr Roentgenol 1993; 160: 189-94. 